\title{
Bacterial microcompartments: catalysis- enhancing metabolic modules for next generation metabolic and biomedical engineering
}

Henning Kirst ${ }^{1,2}$ and Cheryl A. Kerfeld ${ }^{1,2,3^{*}}$

\begin{abstract}
Bacterial cells have long been thought to be simple cells with little spatial organization, but recent research has shown that they exhibit a remarkable degree of subcellular differentiation. Indeed, bacteria even have organelles such as magnetosomes for sensing magnetic fields or gas vesicles controlling cell buoyancy. A functionally diverse group of bacterial organelles are the bacterial microcompartments (BMCs) that fulfill specialized metabolic needs. Modification and reengineering of these BMCs enable innovative approaches for metabolic engineering and nanomedicine.
\end{abstract}

\section{What are bacterial microcompartments?}

Bacterial microcompartments (BMCs) are organelles in prokaryotic cells. In contrast to those of eukaryotes, BMCs are not circumscribed by a phospholipid membrane. Instead, the barrier between the lumen of the organelle and the cytosol is formed by conserved families of proteins that assemble into a selectively permeable shell [1-5]. While the shell architecture is broadly conserved across all BMCs, the encapsulated enzymes vary widely [6]. In general, BMCs are metabolic modules, with the enzymes carrying out a sequence of biochemical reactions, and the shell serving as the interface with the cytosol.

\footnotetext{
* Correspondence: ckerfeld@lbl.gov

'MSU-DOE Plant Research Laboratory, Michigan State University, 612 Wilson Road, East Lansing, Ml 48824, USA

EEnvironmental Genomics and Systems Biology and Molecular Biophysics and Integrated Bioimaging Divisions, Lawrence Berkeley National Laboratory, 1 Cyclotron Road, Berkeley, CA 94720, USA

Full list of author information is available at the end of the article
}

\section{What defines the BMC shell?}

BMCs are defined by the structural proteins that compose their "membranes". There are three structural groups of shell proteins: BMC-H (Pfam00936), which form hexagonal hexamers [1]; BMC-P (Pfam03319), which from pentagonal pentamers $[7,8]$, and $\mathrm{BMC}-\mathrm{T}$ (a tandem fusion of the Pfam00936), which subdivide into two types: trimers $\left(\mathrm{BMC}-\mathrm{T}^{\mathrm{S}}\right)[9-12]$, and stacked dimers of trimers $\left(\mathrm{BMC}-\mathrm{T}^{\mathrm{D}}\right.$ ) (Fig. 1a) [13-15]. Pores, typically at the cyclic axis of symmetry in the hexamers, vary in size (4-7 $\AA$ in diameter) and charge, thereby contributing to selective permeability (Fig. 1a) [1, 13-19]. It has been shown that some $\mathrm{BMC}-\mathrm{H}$ proteins are specifically permeable to anions like $\mathrm{HCO}_{3}^{-}$[20]. The $\mathrm{BMC}-\mathrm{T}^{\mathrm{D}}$ trimers can have gated pores, meaning they have an open and closed conformation (closed conformation shown in Fig. 1a) [13, 14, 18]. The stacking of $B M C-T^{D}$ trimers creates an internal chamber with pores to the lumen of the shell and to the cytosol $[9,13,15,18]$. Their gated pores have been proposed to operate in an airlock fashion with opening and closure controlled by ligand binding [13-15, 18, 21], apparently in a coordinated fashion across the surface of the shell [21]. These structural proteins assemble into a polyhedral shell (Fig. 1b). BMC-H proteins tile into a single layer, but some BMC-H proteins also appear to stack, similar to the $B M C-\mathrm{T}^{\mathrm{D}}$ proteins $[19,22]$. Recently, this has been suggested to be potentially physiologically relevant by dynamically attenuating the shell's permeability depending on environmental conditions [22].

\section{How diverse are BMCs?}

$\mathrm{BMCs}$ are encoded in gene clusters containing the genetic information necessary to form the $\mathrm{BMC}$ and integrate its function with the rest of cellular metabolism [4-6, 23]. This typically includes substrate sensors (regulatory proteins), plasma membrane-associated transporters, enzymes, shell 
A
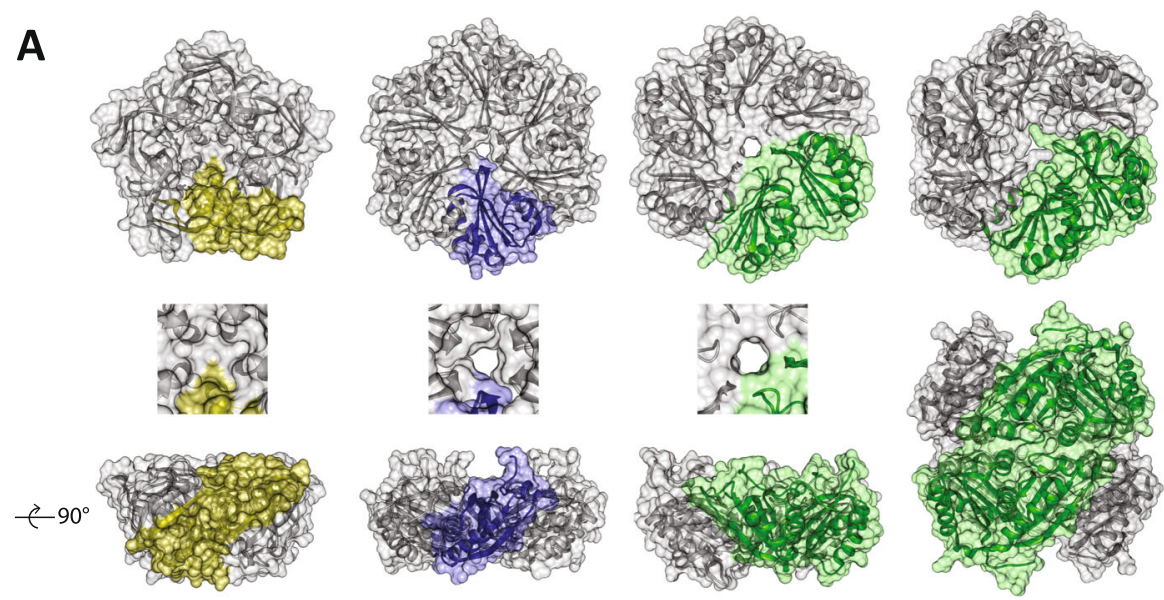

B
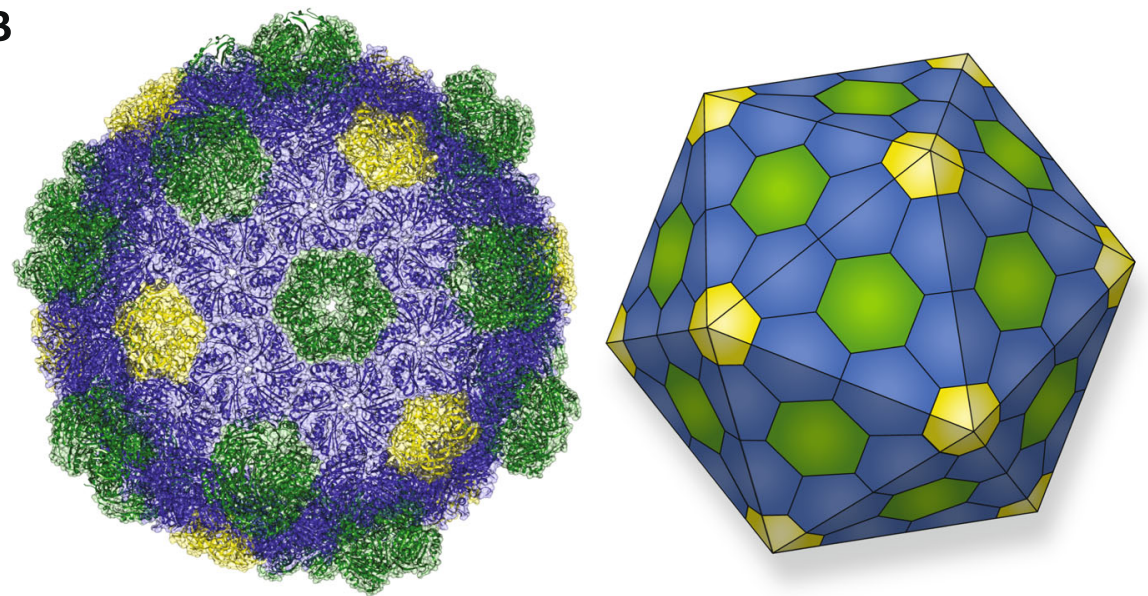

Fig. 1. The BMC structural proteins forming a polyhedral shell. a The four different types of building blocks: BMC-P (pentamer monomer in yellow); BMC-H hexamer (monomer in blue); BMC- $T^{S}$ trimer (monomer in green), and the double stacked BMC-T ${ }^{\mathrm{D}}$ hexamer (monomer in each layer in green). A top view and a side view are shown, as well as a close up of the center for the BMC-P, BMC-H, and BMC- $T^{S}$. The BMC- $T^{D}$ pore can have an open or closed conformation (closed conformation is shown). The shell proteins have a concave and a convex side, the concave side faces outward (towards the top of the side view), while the convex side faces the BMC lumen (towards the bottom of the side view). $\mathbf{b}$ The structure of a BMC shell from Haliangium ochraceum and a schematic of the icosahedral symmetry (BMC-H in blue; BMC-T and BMC-T ${ }^{\mathrm{D}}$ in green; BMC-P in yellow)

proteins, and cytoskeletal elements presumed to control positioning of the organelle (Fig. 2a). The compact arrangement of genes for organelle components and ancillary proteins that support the metabolic integration of the $\mathrm{BMC}$ with the rest of a cell's metabolism likely accounts for their apparent widespread horizontal gene transfer (evident by the same type of BMC being present in very similar genetic arrangements in distantly related bacteria $[4-6,23])$, illustrating the concept of "plug and play" devices in evolution.

BMC loci have been identified in 23 out of the 29 established bacterial phyla [6], and can be divided metabolically into anabolic carboxysomes and catabolic metabolosomes (recently reviewed by [5, 24, 25]). There are two distinct carboxysomes (alpha- and beta-carboxysomes), which differ in the type of $\mathrm{RuBisCO}$ and the conserved carbonic anhydrase they encapsulate. The carbonic anhydrase converts bicarbonate to $\mathrm{CO}_{2}$, the substrate for $\mathrm{Ru}$ BisCO. The co-localization of the enzymes, and the barrier provided by the BMC shell, increases the local concentration of $\mathrm{CO}_{2}$, enhancing the efficiency and selectivity of $\mathrm{Ru}$ BisCO (Fig. 2b) [26, 27].

Metabolosomes are functionally diverse. The types that have been experimentally characterized are propanediol utilizing (PDU and GRM3) [28-30], ethanolamine utilizing (EUT) [31], fucose and rhamnose utilizing (GRM5 and PVM) [32, 33], 1-amino-2-propanol utilizing (RMM) [34, 35] and choline utilizing (GRM2) [36, 37]. Even though these metabolosomes have different substrates, they share a common core biochemistry which consists of a substrate-defining signature enzyme, an aldehyde dehydrogenase (AldDH), 


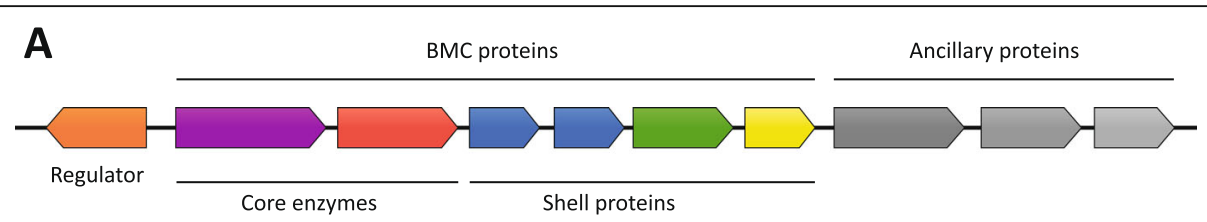

B
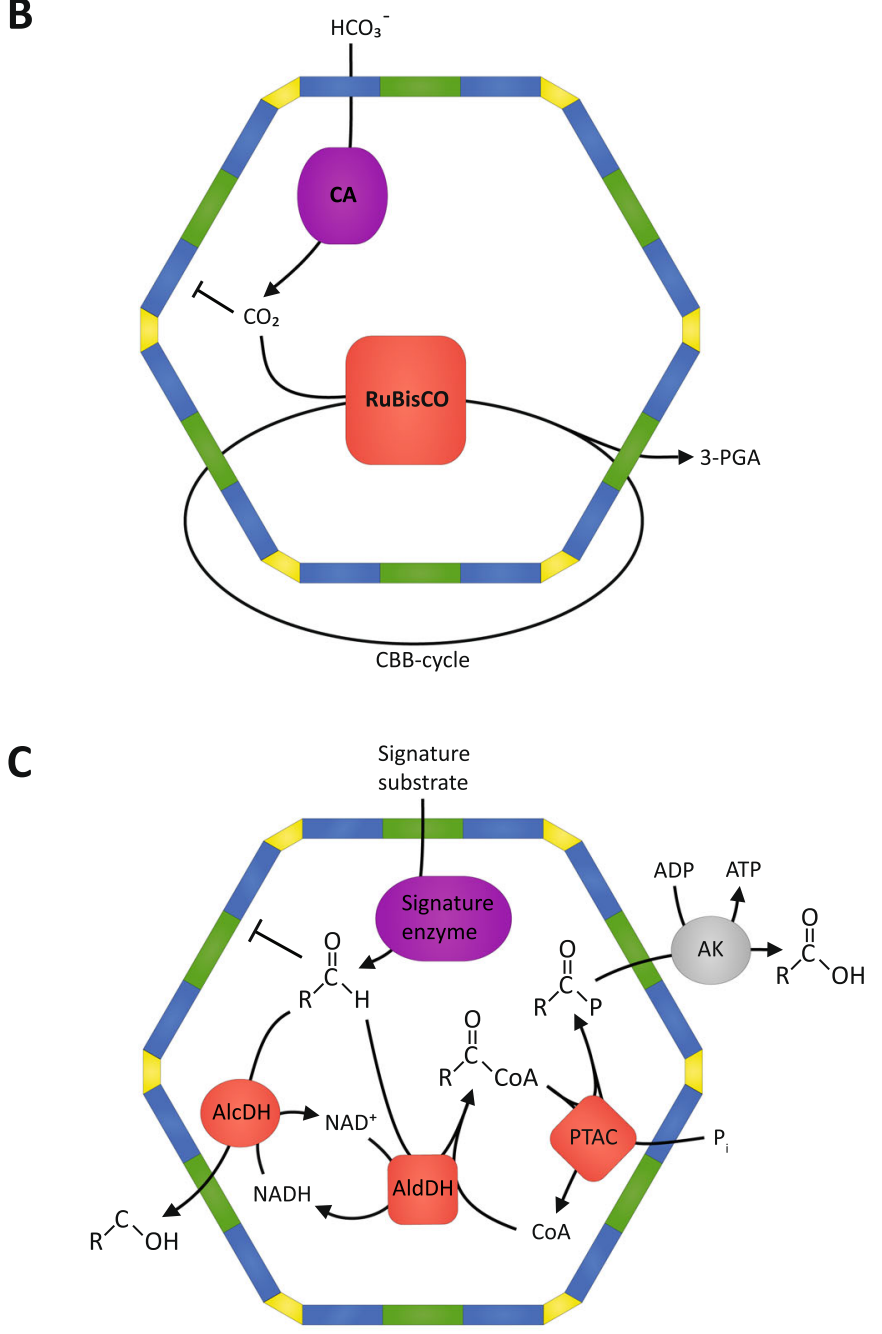

Fig. 2 BMC genetic and metabolic modularity. a Schematic of a BMC gene locus containing a transcriptional regulator (orange) presumably controlling the expression of the BMC operon, the enzymatic core (purple and red), the structural shell proteins (blue, green, and yellow) forming the BMC and the ancillary proteins positioning and metabolically integrating the BMC into the cell (gray). $\mathbf{b}$ Schematic function of the carboxysome. The shell acts as a barrier to concentrate the $\mathrm{CO}_{2}$ and potentially exclude the competitive inhibitor oxygen within the $\mathrm{BMC}$, enabling RuBisCO to operate more efficiently. 3-PGA 3-phosphoglycerate. c Schematic function of metabolosomes. The toxic aldehyde intermediate is contained and detoxified within the BMC. COA coenzyme $\mathrm{A}$, $P_{\mathrm{i}}$ inorganic phosphate

an alcohol dehydrogenase (AlcDH), and a phosphotransacylase (PTAC) (Fig. 2c). The signature enzyme generates an aldehyde which is then processed by the AlcDH and the coenzyme A-dependent AldDH to from an alcohol and a coenzyme A derivate of a carboxylic acid. The PTAC regenerates the coenzyme A, producing a phosphate ester that is used by a kinase to generate ATP. The aldehyde intermediate is a volatile toxin, impairing protein functions and damaging DNA, which can ultimately lead to cell death [38]. The metabolosome sequesters and detoxifies aldehyde intermediates [33, 39-41] and additionally prevents carbon loss due to its volatility [42].

Our group is now updating our survey of BMC loci found in sequenced genomes. We find that the numbers and diversity of BMCs have expanded substantially since 
2014 [6], due at least in part to the recent emphasis on sequencing the genomes of microbial "dark matter" [43, 44]. Some are novel BMC loci of unknown function that do not fit the metabolosome or carboxysome paradigm (unpublished data) [6], indicating that BMCs are metabolically more diverse than previously thought and function in unexplored ways to give the organism a competitive advantage.

\section{How do the enzymes get into the BMC lumen?}

There is no known mechanism for proteins to cross the BMC shell. Studies of carboxysome assembly have shown that enzymatic cargo coalesces and then is encapsulated by the shell proteins (Fig. 3a) [45], or cargo and shell assemble simultaneously (Fig. 3b) [46]. Some core proteins of beta-carboxysomes and metabolosomes contain an encapsulation peptide, which are typically found at the $\mathrm{N}$ - or $\mathrm{C}$-terminus of a cargo protein. Encapsulation peptides are composed of one or more segments of $\sim 20$ amino acids that are predicted to form an amphipathic $\alpha$-helix [47]. These encapsulation peptides seem to facilitate aggregation of the core enzymes, and also interact with the shell proteins to form a complete assembled BMC in a core-first process (Fig. 3a) [48-53]. In the case of the alpha-carboxysomes, complete BMC formation is facilitated by an intrinsically disordered protein, CsoS2, which interacts with the cargo enzymes as well with the shell proteins [54-56]. This leads to concurrent assembly of shell and enzymatic core in alpha-carboxysomes which has been observed in detail using cryo-electron tomography (Fig. 3b) [57].

\section{How are BMCs being adapted for bioengineering?}

The first reports of bioengineering of BMCs focused on transplanting the PDU BMC locus from Citrobacter freundii to Escherichia coli [58]. The BMC genes were expressed, enabling the transgenic $E$. coli to grow on propanediol. More recently a PDU locus was transferred to a variety of species (E. coli, Salmonella bongori, Klebsiella pneumoniae, Cronobacter sakazakii, Serratia marcescens, and Pseudomonas spp.), likewise resulting in propanediol catabolism and BMC formation [59]. In two different studies, the genes of an alpha-carboxysome have been transferred to $E$. coli and Corynebacterium glutamicum and their expression resulted in RuBisCO activity [60, 61].

BMC bioengineering efforts have extended to plants, with the aim to enhance $\mathrm{CO}_{2}$ fixation by installing carboxysomes in chloroplasts (recently reviewed by [62]). Beta-carboxysome genes [63] and an engineered alphacarboxysome operon [64] have been transferred to chloroplasts of Nicotiana benthamiana and Nicotiana tabacum, respectively. Carboxysome-like structures formed in the chloroplasts of these transgenic plants and even allowed for photo-autotrophic growth of plant $\mathrm{RuBisCO}$ knockout mutants in the latter case.

Taking advantage of the self-assembly process, BMC shells can be generated by expressing the shell proteins without the cargo proteins [65-67]. Such shells can be utilized for "bottom up" approaches to construct synthetic BMCs carrying out entirely novel functions. This approach was applied to take up and store polyphosphate in C. freundii [68]. A polyphosphate kinase tagged with an encapsulation peptide was introduced into a PDU BMC shell. The higher amount of cellular polyphosphate in the transgenic cells was presumably caused by preventing exophosphatases access to the encapsulated polyphosphate.

\section{What innovative technologies are being developed to enable the full potential of bioengineering BMCs?}

There are many potential applications for engineered BMCs, including serving as nano-factories for biochemical production or as novel drug delivery devices. However, methods need to be developed enabling the modification of every aspect of the shell, like loading heterologous cargo, engineering the permeability of the pores, and controlling the assembly process.

\section{Encapsulation of non-endogenous cargo}

Being able to control which enzymes are encapsulated by the shell enables metabolically repurposing the BMC or the use of shell for entirely new applications, like bioremediation or chemical storage.

Native encapsulation peptides have been fused to heterologous cargo in order to target them into the lumen of the shells. However, this has been inefficient, with only very little cargo successfully incorporated into the BMC $[66,67,69]$, indicating that we do not fully understand the determinants of enzyme encapsulation. However, engineered solutions have been developed that allow efficient and effective encapsulation of cargo. For example, the SpyTag/SpyCatcher bacterial split adhesin domains [70] have been adapted to bind cargo covalently to the inside of the shell. The SpyCatcher component was inserted into a lumen-facing loop of a BMC- $\mathrm{T}^{\mathrm{S}}$ protein, and fusing the SpyTag to heterologous cargo enabled it to be specifically and efficiently encapsulated [71]. In another approach, a BMC-H protein was circularly permuted to project the $\mathrm{N}$ - and $\mathrm{C}$-termini, which are naturally on the external side of the shell, into the lumen for fusion of cargo [72, 73]. This can be combined with using the specific interaction of two coiledcoil domains, one fused to a circularly permuted BMC$\mathrm{H}$ and the other fused to the heterologous cargo to load the BMC shell [72]. Cargo can also be loaded into the 


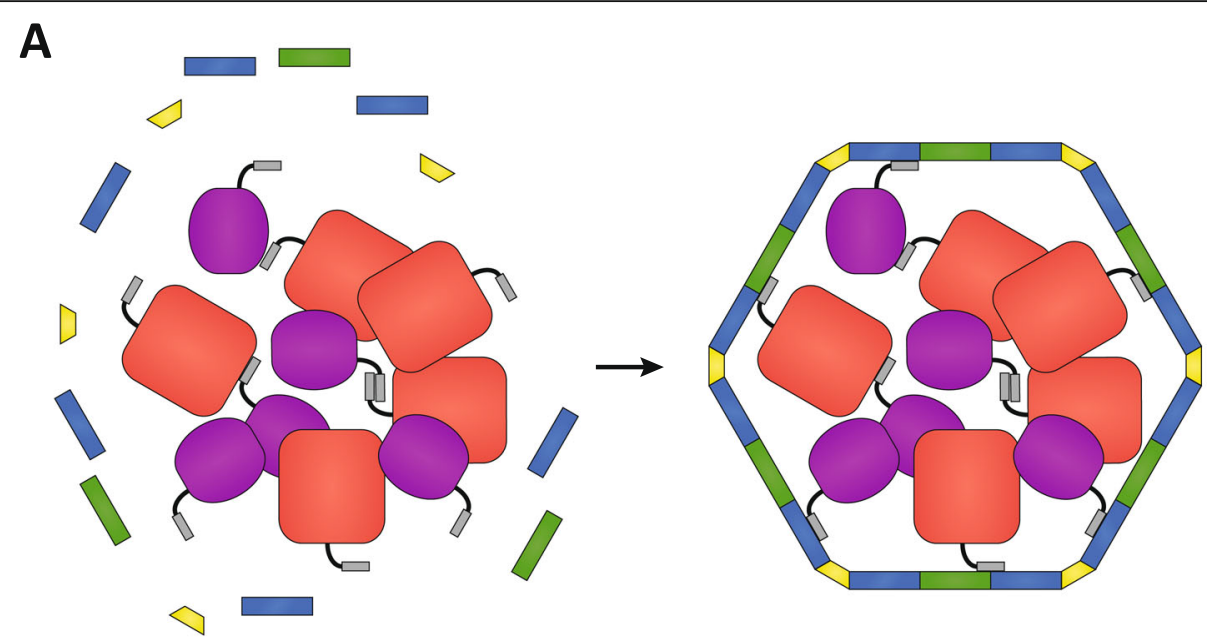

B

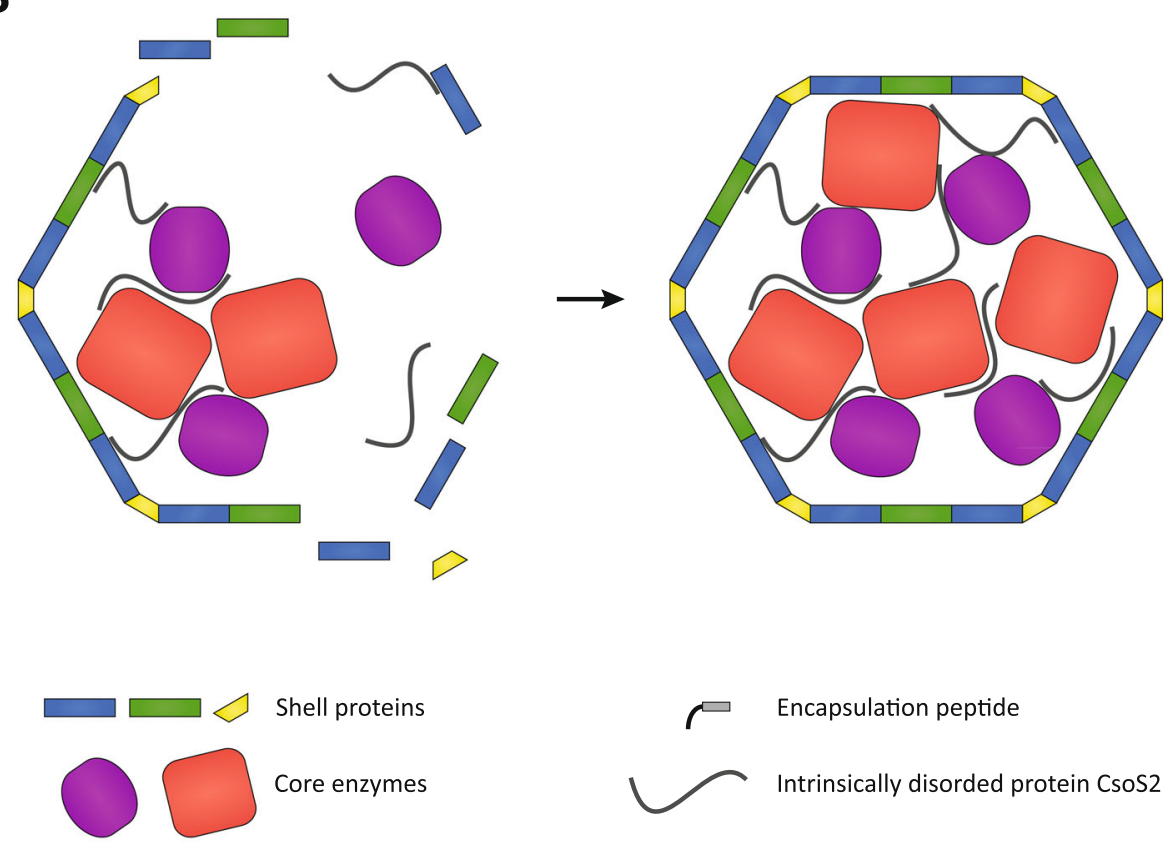

Fig. 3. Assembly process of BMCs. a Core-first assembly (beta-carboxysomes and metabolosomes). Aggregation of the core enzymes is facilitated by the encapsulation peptide in combination with other assembly proteins. After aggregation the encapsulation peptide interacts with the shell proteins to from a complete BMC. b Concomitant assembly (alpha carboxysomes): simultaneous core aggregation and shell protein recruitment is enabled by the intrinsically disordered protein CsoS2

shell based on electrostatic attraction. The luminal surface of a BMC-H protein was modified to be positively charged to promote the encapsulation of negatively charged biotic or abiotic cargo [74].

\section{Engineering shell permeability}

In order to construct effective synthetic BMCs, the shell permeability would need to be tuned to fit its catalytic function. The feasibility of pore engineering has been demonstrated; changing the residues that surround the pores alters their size and permeability, without interfering with the shell assembly $[17,66,75]$. But manipulation of shell permeability is not limited to metabolite selectivity; a redox active $\mathrm{FeS}$ cluster has been incorporated into a $B M C-T^{S}$ pore to enable electron flow across the shell [12]. This enables the potential for designing BMCs that require or generate electrons. A key challenge for BMC engineering is the development of tools for directly 
measuring shell permeability to enable rapid prototyping of shell designs.

\section{In vitro assembly of BMC shells}

The recently developed method of assembling BMC shells in vitro will facilitate rapid prototyping [74]. Moreover, in vitro assembly allows encapsulation of toxic and/or abiotic cargo into BMCs, which is not possible in vivo; that greatly expands the versatility of BMCs to function in cell-free chemical catalysis or in nanomedicine to deliver cytotoxins to cancer cells. Furthermore, mixing functional groups carrying structural proteins in different stoichiometries allows for rapid, highthroughput screening of the most effective combination or most robust BMC shell assembly.

\section{What are the emerging applications of BMCs? Increasing efficiency in metabolic engineering}

The enormous complexity of metabolic pathways, their regulation, and their crosstalk creates major obstacles for metabolic engineering, because small changes made to the system, can often have unpredictable consequences [76]. Thus, effective production strains need to go through many rounds of time-consuming optimization (recently reviewed in [77]). Ideally, an autonomous metabolic module is introduced decoupled from the cell's regulatory and metabolic networks. Selfassembling, easy-to-modify and interspecies transferable BMCs are potential devices for the next generation of metabolic engineering (Fig. 4).

\section{Avoiding metabolite cross-talk}

The components of the cell and its bioproducts are synthesized from a small set of precursors that feed into many different pathways [77]. If a large flux through a pathway is desired for maximum product yield, it requires a steadily available supply of precursors. Thus, metabolic cross-talk of the production pathway with existing endogenous metabolic pathways is unavoidable. Deletion of the competing pathways is not possible if these pathways are essential to the cell and downregulation needs to be fine tuned not to interfere with growth. In fact, identification of metabolic cross-talk and its effective solution is one reason for the protracted development times of efficient production strains [77]. An example of such unwanted cross-talk in metabolic engineering occurs in the synthesis of isoprenoids. Isoprenoids are a large and diverse group of natural compounds some of which are used as performance materials or as therapeutics and thus are often targeted in metabolic engineering efforts [78, 79]. All isoprenoids are synthesized by the basic building blocks isopentyl-pyrophosphate (IPP) and dimethylallyl-pyrophosphate (DMAPP). They are condensed to form the monoterpene geranyl pyrophosphate and the addition of another IPP forms the sesquiterpene farnesyl pyrophosphate (FPP). These pyrophosphate intermediates are branching off into many different isoprenoids, all of which need to be controlled for efficient production of the isoprenoid of interest. Synthetic BMCs encapsulating the production pathway can spatially insulate the intermediates from the rest of the cell, thus providing a private substrate pool for the enzyme that would otherwise need to compete for substrates with off-branching pathways if located in the cytosol.

\section{Improving enzyme kinetics through scaffolding and substrate concentration}

Simulations indicate that compartmentalization of enzymes and the consequent local increase in intermediate substrate concentration can significantly improve catalytic turnover rates [80]. A metabolite intermediate is more likely to interact with a downstream enzyme in the compartment rather than diffusing away [81]. This concept

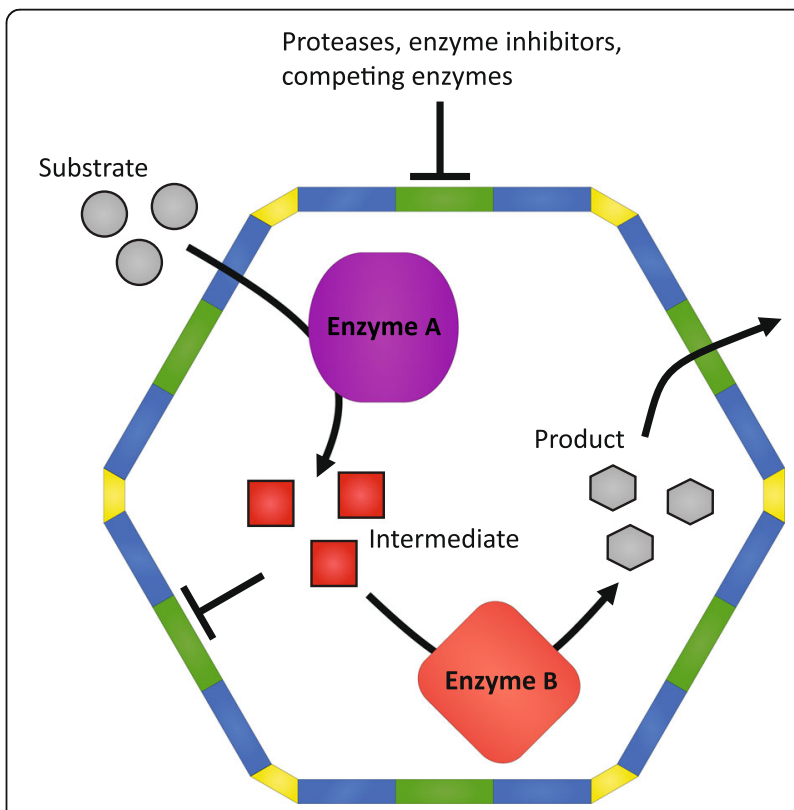

Fig. 4. Schematic of possible synthetic BMC functions in metabolic engineering. The semipermeable shell allows a substrate to diffuse into the lumen that is then processed by enzyme A. The intermediate (red) can be a toxin that needs to be contained, an unstable molecule that requires fast processing, or a metabolite that can be used by off-branching metabolic pathways. In all these cases encapsulation of the enzymes into a BMC would eliminate such problems. Enzyme B can be a promiscuous or slow enzyme, operating more efficiently when given only one specific substrate in high concentrations. The shell also can act to stabilize proteins by preventing proteolytic degradation and decouples the pathway from endogenous regulation by preventing inhibitors from accessing the encapsulated enzymes 
has been used in synthetic enzyme scaffolds to increase flux through a biosynthetic pathway, recently reviewed by [82]. BMCs have naturally evolved to function as threedimensional enzyme scaffolds and improve metabolic flux. In contrast to synthetic scaffolds developed to date, they offer a more sophisticated means of controlling metabolite flux by providing a semi-permeable shell. Because they are structurally precisely defined, loading strategies and modifications can be made accurately with a predictable outcome and thus might offer an advanced alternative to the existing synthetic enzyme scaffolds.

\section{Containment of cytotoxic metabolic intermediates}

Bioengineering efforts are increasingly revealing issues with toxicity of intermediates due to higher steady state concentrations of metabolic intermediates when directing large amounts of carbon into the production pathway [83, 84]. One example is pyrophosphates like IPP and DMAPP needed for the generation of isoprenoids. These have been reported to be toxic to the cell when accumulated after engineering a host strain [83]. Nature's solution to such problems is the compartmentalization of the toxic intermediategenerating metabolic step, e.g., containment of the aldehyde intermediate in metabolosomes (Fig. 3c). Next-generation metabolic engineering can take existing metabolosomes as blueprints and refunctionalize them to contain and process a specific toxic intermediate. Furthermore, they will likely prove useful for structuring metabolism in the context of cell-free metabolic engineering [85].

\section{Maximizing substrate specificity and minimizing metabolite damage}

Like carboxysome-encapsulated RuBisCO (Fig. 3b), many enzymes are not entirely substrate specific, and damaged metabolites can be generated when an enzyme mistakenly uses a wrong substrate [86]. This is wasteful and can even be cytotoxic. The BMC shell can function to enrich the desired substrate in the vicinity of promiscuous enzymes to increase the yields of the product. This can be done by either engineering the permeability of the pores or by encapsulation of substrate-specific upstream metabolic steps.

Another form of metabolite damage is caused by spontaneous chemical reaction of the substrate with itself or with other molecules [86]. In metabolic engineering, metabolite damage remains a challenge because often little is known about spontaneous reactions of the metabolic intermediates within the chemically complex environment of the cytosol. Compartmentalizing reactions that require chemically sensitive cofactors is a natural function of metabolosomes (Fig. 3c).

\section{BMCs as a tool to engineer microbial communities}

Many metabolosomes enable microbes to utilize specific energy, carbon, and nitrogen sources that are niche specific.
Accordingly, BMCs contribute to both forming and distorting bacterial communities. An environment in which BMC-containing strains are common and potentially shape the community are hydraulically fractured shales $[87,88]$. Recent studies indicate that these communities impact gas and oil production. Negative impacts arise from corrosion which is attributed to the most abundant members in these shales, Halanaerobium bacteria [87, 89-91]. These organisms utilize ethanolamine and the trimethylamine (TMA) produced by them is then taken up by Methanohalophilus bacteria [88]. The EUT (ethanolamine utilizing) BMC and many other BMC types are frequently found in the sequenced genomes of Halanaerobium prevailing in shales [88], suggesting that these BMCs could play a major role in shaping the subterranean bacterial community. Clearly, more research is needed to investigate the connection of the BMCs to the success of Halanaerobium species, which in turn might offer a potential to reshape these communities to alleviate the negative corrosiveness associated with Halanaerobium.

BMC-containing bacteria can also have an influence on human health by allowing a harmful species to succeed in nutrient poor environments of our body. For example, a pathogenic E. coli encoding a EUT BMC is able to metabolize ethanolamine and thus gains a competitive advantage over the normal intestinal flora when other nutrients are limited [92]. This can distort the bacterial community in the intestine in favor of the pathogen. A similar competitive advantage was found for the pathogen Salmonella enterica serovar typhimurium, also expressing a EUT BMC [93]. More recently, a choline-utilizing BMC has been characterized in uropathogenic E. coli [37]. Proliferation of such pathogens could potentially be prevented or treated upon introduction of a competitor to the pathogens carrying a transgenic BMC utilizing the same substrates. Such a probiotic strain could help shift the bacterial community back to a healthy intestinal flora.

\section{What potential do BMCs have in biomedicine?}

Nanomedicine includes the development of nanoparticles to serve as drug-delivery systems and platforms for designer vaccines [94-97]. Nanoparticles that can encapsulate therapeutic cargo have been extensively studied in recent years, yielding a diverse arsenal of useful nanostructures ranging from virus-like particles to inorganic silica nanoparticles [98]. BMC shells also have the potential to function as nanoparticle chassis for nanomedicine. For example, shell proteins could be engineered to incorporate an array of suitable peptides already developed for existing nanoparticles to facilitate active targeting of the shell to pathogens or cancer cells, tumor and cell penetration, and endosomal escape (Fig. 5a) [99]. Additionally, in vitro BMC assembly permits the encapsulation of cytotoxic therapeutics used in cancer therapy 


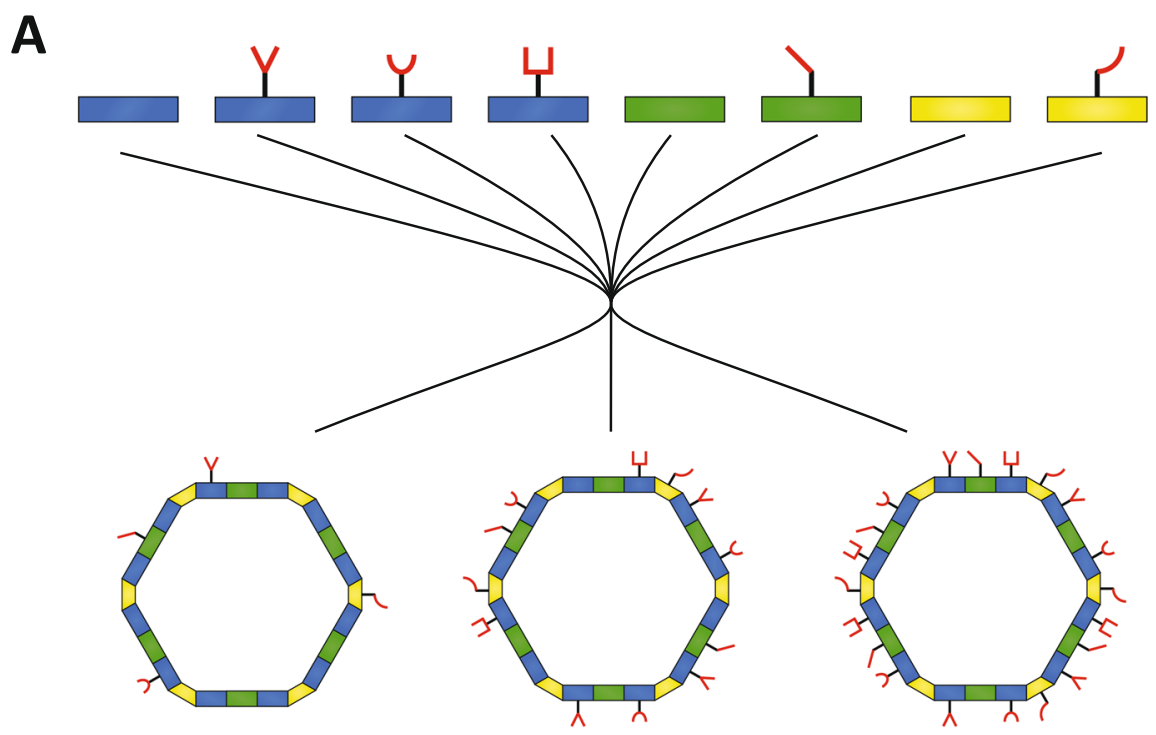

B
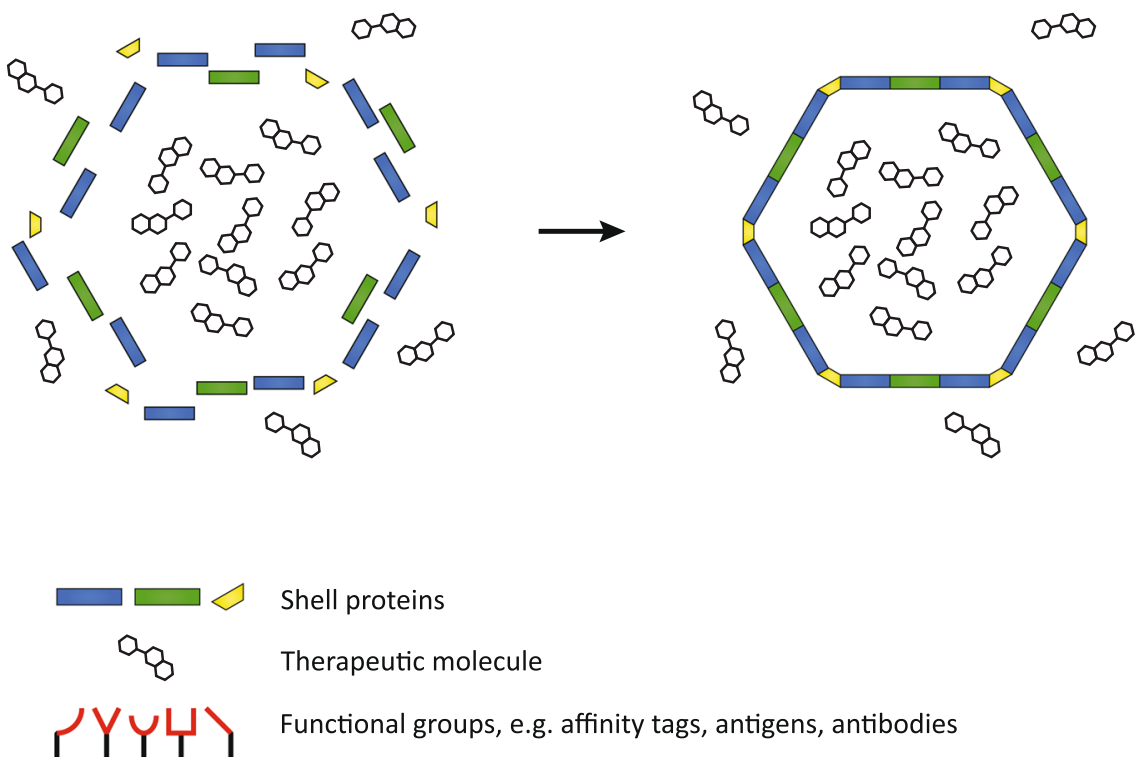

Fig. 5. Possible applications of $B M C$ in vitro assembly for nanomedicine. a High throughput testing of different combinations and densities of functional groups on a BMC. The structural proteins carrying various functional groups can be mixed together in different stoichiometries to generate many different versions of nanoparticles. $\mathbf{b}$ In vitro BMC assembly in a solution of therapeutic toxin can be used for the development of novel drug delivery systems

(Fig. 5b). A concern may be antigenicity of the BMC shell, limiting its application; this has yet to be tested. However, existing methods to modify the antigenicity of nanoparticles could also be used for BMCs such as the widely used PEGylation [100].

\section{BMCs as chassis for designer vaccines}

Multiple parameters are important to trigger potent immune responses, including the size and geometry of the pathogen as a whole, as well as antigen density and distribution [101]. Modern vaccines can mimic these properties by utilizing nanoparticles as chassis to present antigens from a pathogen, recently reviewed by [102, 103]. BMC shells are geometrically comparable to icosahedral viruses and also have roughly the same size, ranging from 40 to $200 \mathrm{~nm}$ in diameter depending on the type of BMC [104, 105]. The model BMC shell from Haliangium ochraceum forms homogeneous particles of 

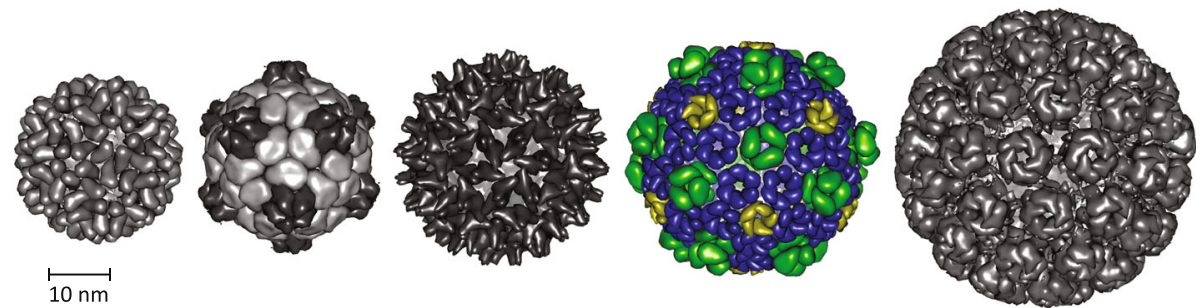

Fig. 6. The size and geometry of virus-like particles used in biomedical engineering in comparison with the BMC shell from Haliangium ochraceum. From left to right: cowpea chlorotic mottle virus (PDB ID 1cwp), cowpea mosaic virus (PDB ID 5fmo), hepatitis B virus capsid (PDB ID 1QGT), Haliangium ochraceum BMC (PDB ID 6MZX), and murine polyomavirus (PDB ID 1sid)

$40 \mathrm{~nm}$ diameter [104], which is very similar to virus-like particles currently used as scaffolds in biomedical engineering (Fig. 6). The Haliangium ochraceum BMC shell can tolerate peptide fusions to its constituent proteins, allowing for its efficient assembly [71, 74], and permitting the presentation of a diverse set of antigens. This flexibility in modifying different shell proteins in combination with the in vitro assembly method would allow high throughput sceening of different combinations and densities of antigens for the most potent immune response (Fig. 5b).

\section{Acknowledgements}

The authors thank Dr. John Steele and Dr. Markus Sutter for helpful discussions. This work was supported by the NSF, award number MCB 1733552, and the National Institutes of Health, National Institute of Allergy and Infectious Diseases (NIAID) grant 1R01Al114975-01.

\section{Authors' contributions}

Both authors wrote, read and approved the final manuscript.

\section{Competing interests}

The authors declare that they have no competing interests.

\section{Author details}

${ }^{1}$ MSU-DOE Plant Research Laboratory, Michigan State University, 612 Wilson Road, East Lansing, Ml 48824, USA. ${ }^{2}$ Environmental Genomics and Systems Biology and Molecular Biophysics and Integrated Bioimaging Divisions, Lawrence Berkeley National Laboratory, 1 Cyclotron Road, Berkeley, CA 94720, USA. ${ }^{3}$ Department of Biochemistry and Molecular Biology, Michigan State University, 603 Wilson Road, East Lansing, MI 48824, USA.

Received: 22 August 2019 Accepted: 23 August 2019

Published online: 10 October 2019

\section{References}

1. Kerfeld CA, Sawaya MR, Tanaka S, Nguyen CV, Phillips M, Beeby M, et al. Protein structures forming the shell of primitive bacterial organelles. Science. 2005;309:936-8. https://doi.org/10.1126/science.1113397.

2. Kerfeld CA, Heinhorst S, Cannon GC. Bacterial microcompartments. Annu Rev Microbiol. 2010;64:391-408. https://doi.org/10.1146/annurev.micro.1124 08.134211

3. Yeates TO, Kerfeld C, Heinhorst S, Cannon GC, Shively JM. Protein-based organelles in bacteria: carboxysomes and related microcompartments. Nat Rev Microbiol. 2008;6:681-91. https://doi.org/10.1038/nrmicro1913.

4. Kerfeld CA, Erbilgin O. Bacterial microcompartments and the modular construction of microbial metabolism. Trends Microbiol. 2015;23:22-34. https://doi.org/10.1016/j.tim.2014.10.003.

5. Kerfeld CA, Aussignargues C, Zarzycki J, Cai F, Sutter M. Bacterial microcompartments. Nat Rev Microbiol. 2018;16:277-90. https://doi.org/10.1 038/nrmicro.2018.10.
6. Axen SD, Erbilgin O, Kerfeld CA. A taxonomy of bacterial microcompartment loci constructed by a novel scoring method. PLoS Comput Biol. 2014;10: e1003898. https://doi.org/10.1371/journal.pcbi.1003898.

7. Tanaka S, Kerfeld CA, Sawaya MR, Cai F, Heinhorst S, Cannon GC, et al. Atomic-level models of the bacterial carboxysome shell. Science. 2008;319: 1083-6. https://doi.org/10.1126/science.1151458.

8. Sutter M, Wilson SC, Deutsch S, Kerfeld CA. Two new high-resolution crystal structures of carboxysome pentamer proteins reveal high structural conservation of $\mathrm{CcmL}$ orthologs among distantly related cyanobacterial species. Photosynth Res. 2013:118:9-16.

9. Sagermann M, Ohtaki A, Nikolakakis K. Crystal structure of the EutL shell protein of the ethanolamine ammonia lyase microcompartment. Proc Natl Acad Sci U S A. 2009;106:8883-7. https://doi.org/10.1073/pnas.0902324106.

10. Crowley CS, Cascio D, Sawaya MR, Kopstein JS, Bobik T, Yeates TO. Structural insight into the mechanisms of transport across the Salmonella enterica Pdu microcompartment shell. J Biol Chem. 2010;285:37838-46. https://doi. org/10.1074/jbc.M110.160580.

11. Heldt D, Frank S, Seyedarabi A, Ladikis D, Parsons JB, Warren MJ, et al. Structure of a trimeric bacterial microcompartment shell protein, EtuB, associated with ethanol utilization in Clostridium kluyveri. Biochem J. 2009; 423:199-207. https://doi.org/10.1042/BJ20090780.

12. Aussignargues C, Pandelia ME, Sutter M, Plegaria JS, Zarzycki J, Turmo A, et al. Structure and function of a bacterial microcompartment shell protein engineered to bind a [4Fe-4S] cluster. J Am Chem Soc. 2016;138:5262-70.

13. Cai F, Sutter M, Cameron JC, Stanley DN, Kinney JN, Kerfeld CA. The structure of $\mathrm{CcmP}$, a tandem bacterial microcompartment domain protein from the $\beta$-carboxysome, forms a subcompartment within a microcompartment. J Biol Chem. 2013;288:16055-63.

14. Klein MG, Zwart P, Bagby SC, Cai F, Chisholm SW, Heinhorst S, et al. Identification and structural analysis of a novel carboxysome shell protein with implications for metabolite transport. J Mol Biol. 2009;392:319-33. https://doi.org/10.1016/j.jmb.2009.03.056.

15. Larsson AM, Hasse D, Valegård K, Andersson I. Crystal structures of $\beta$ carboxysome shell protein CcmP: ligand binding correlates with the closed or open central pore. J Exp Bot. 2017;68:3857-67.

16. Crowley CS, Sawaya MR, Bobik TA, Yeates TO. Structure of the PduU shell protein from the Pdu microcompartment of Salmonella. Structure. 2008;16: 1324-32. https://doi.org/10.1016/j.str.2008.05.013.

17. Chowdhury C, Chun S, Pang A, Sawaya MR, Sinha S, Yeates TO. Selective molecular transport through the protein shell of a bacterial microcompartment organelle. Proc Natl Acad Sci U S A. 2015;112:2990-5. https://doi.org/10.1073/pnas.1423672112.

18. Mallette E, Kimber MS. A complete structural inventory of the mycobacterial microcompartment shell proteins constrains models of global architecture and transport. J Biol Chem. 2017;292:1197-210. https://doi.org/10.1074/jbc. M116.754093.

19. Samborska B, Kimber MS. A dodecameric C cmK2 structure suggests betacarboxysomal shell facets have a double-layered organization. Structure. 2012;20:1353-62.

20. Mahinthichaichan P, Morris DM, Wang Y, Jensen GJ, Tajkhorshid E. Selective permeability of carboxysome shell pores to anionic molecules. J Phys Chem B. 2018;122:9110-8.

21. Greber BJ, Sutter M, Kerfeld CA. The plasticity of molecular interactions governs bacterial microcompartment shell assembly. Structure. 2019. https://doi.org/10.1016/j.str.2019.01.017. 
22. Sommer M, Sutter M, Gupta S, Kirst H, Turmo A, Lechno-Yossef S, et al Heterohexamers formed by CcmK3 and CcmK4 increase the complexity of beta carboxysome shells. Plant Physiol. 2019;179:156-67. https://doi.org/1 0.1104/pp.18.01190.

23. Kerfeld CA. A bioarchitectonic approach to the modular engineering of metabolism. Philos Trans R Soc Lond Ser B Biol Sci. 2017;372:20160387. https://doi.org/10.1098/rstb.2016.0387.

24. Turmo A, Gonzalez-Esquer CR, Kerfeld CA. Carboxysomes: metabolic modules for CO2 fixation. FEMS Microbiol Lett. 2017;364. https:/doi.org/10.1093/femsle/fnx176.

25. Ferlez B, Sutter M, Kerfeld CA. Glycyl radical enzyme-associated microcompartments: redox-replete bacterial organelles. MBio. 2019;10: e02327-18. https://doi.org/10.1128/mBio.02327-18.

26. Kerfeld CA, Melnicki MR. Assembly, function and evolution of cyanobacterial carboxysomes. Curr Opin Plant Biol. 2016;31:66-75. https://doi.org/10.1016/j. pbi.2016.03.009.

27. Rae BD, Long BM, Badger MR, Price GD. Functions, compositions, and evolution of the two types of carboxysomes: polyhedral microcompartments that facilitate CO2 fixation in cyanobacteria and some proteobacteria. Microbiol Mol Biol Rev. 2013;77:357-79.

28. Bobik TA, Havemann GD, Busch RJ, Williams DS, Aldrich HC. The propanediol utilization (pdu) operon of Salmonella enterica serovar typhimurium LT2 includes genes necessary for formation of polyhedral organelles involved in coenzyme B12-dependent 1,2-propanediol degradation. J Bacteriol. 1999;181:5967-75.

29. Zarzycki J, Sutter M, Cortina NS, Erb TJ, Kerfeld CA. In vitro characterization and concerted function of three core enzymes of a glycyl radical enzyme associated bacterial microcompartment. Sci Rep. 2017;7:42757. https://doi. org/10.1038/srep42757

30. Schindel HS, Karty JA, McKinlay JB, Bauer CE. Characterization of a glycyl radical enzyme bacterial microcompartment pathway in Rhodobacter capsulatus. J Bacteriol. 2019;201:e00343-18. https://doi.org/10.1128/JB.00343-18.

31. Kofoid E, Rappleye C, Stojiljkovic I, Roth J. The 17-gene ethanolamine (eut) operon of Salmonella typhimurium encodes five homologues of carboxysome shell proteins. J Bacteriol. 1999;181:5317-29.

32. Petit E, LaTouf WG, Coppi MV, Warnick TA, Currie D, Romashko I, et al. Involvement of a bacterial microcompartment in the metabolism of fucose and rhamnose by Clostridium phytofermentans. PLoS One. 2013;8:e54337. https://doi.org/10.1371/journal.pone.0054337.

33. Erbilgin O, McDonald KL, Kerfeld CA. Characterization of a planctomycetal organelle: a novel bacterial microcompartment for the aerobic degradation of plant saccharides. Appl Environ Microbiol. 2014;80:2193-205. https://doi. org/10.1128/AEM.03887-13.

34. Kataoka M, Nakamura Y, Urano N, Ishige T, Shi G, Kita S, et al. A novel NADP+-dependent I-1-amino-2-propanol dehydrogenase from Rhodococcus erythropolis MAK154: a promising enzyme for the production of double chiral aminoalcohols. Lett Appl Microbiol. 2006;43:430-5. https:// doi.org/10.1111/j.1472-765X.2006.01970.x.

35. Mallette E, Kimber MS. Structural and kinetic characterization of (S)-1-amino2-propanol kinase from the aminoacetone utilization microcompartment of Mycobacterium smegmatis. J Biol Chem. 2018. https://doi.org/10.1074/jbc. RA118.005485.

36. Craciun S, Balskus EP. Microbial conversion of choline to trimethylamine requires a glycyl radical enzyme. Proc Natl Acad Sci U S A. 2012;109:2130712. https://doi.org/10.1073/pnas.1215689109.

37. Herring TI, Harris TN, Chowdhury C, Mohanty SK, Bobik TA. A bacterial microcompartment is used for choline fermentation by Escherichia coli 536. J Bacteriol. 2018;200:e00764-17. https://doi.org/10.1128/JB.00764-17.

38. O'Brien PJ, Siraki AG, Shangari N. Aldehyde sources, metabolism, molecular toxicity mechanisms, and possible effects on human health. Crit Rev Toxicol. 2005;35:609-62. https://doi.org/10.1080/10408440591 002183.

39. Rondon MR, Horswill AR, Escalante-Semerena JC. DNA polymerase I function is required for the utilization of ethanolamine, 1,2-propanediol, and propionate by Salmonella typhimurium LT2. J Bacteriol. 1995;177:7119-24. https://doi.org/10.1128/jb.177.24.7119-7124.1995.

40. Sampson EM, Bobik TA. Microcompartments for B12-dependent 1,2propanediol degradation provide protection from DNA and cellular damage by a reactive metabolic intermediate. J Bacteriol. 2008;190:2966-71.

41. Havemann GD, Sampson EM, Bobik TA. PduA is a shell protein of polyhedral organelles involved in coenzyme B12-dependent degradation of 1,2-propanediol in Salmonella enterica serovar typhimurium LT2. J Bacteriol. 2002;184:1253-61.
42. Penrod JT, Roth JR. Conserving a volatile metabolite: a role for carboxysome-like organelles in Salmonella enterica. J Bacteriol. 2006;188: 2865-74. https://doi.org/10.1128/JB.188.8.2865.

43. Rinke C, Schwientek P, Sczyrba A, Ivanova NN, Anderson IJ, Cheng J-F, et al. Insights into the phylogeny and coding potential of microbial dark matter. Nature. 2013:499:431 https://doi.org/10.1038/nature12352.

44. Woyke T, Doud DFR, Schulz F. The trajectory of microbial single-cell sequencing. Nat Methods. 2017;14:1045 https://doi.org/10.1038/nmeth.4469.

45. Cameron JC, Wilson SC, Bernstein SL, Kerfeld CA. Biogenesis of a bacterial organelle: the carboxysome assembly pathway. Cell. 2013;155:1131-40. https://doi.org/10.1016/j.cell.2013.10.044

46. lancu CV, Morris DM, Dou Z, Heinhorst S, Cannon GC, Jensen GJ. Organization, structure, and assembly of alpha-carboxysomes determined by electron cryotomography of intact cells. J Mol Biol. 2010;396:105-17. https://doi.org/10.1016/j.jmb.2009.11.019.

47. Kinney JN, Salmeen A, Cai F, Kerfeld CA. Elucidating essential role of conserved carboxysomal protein $\mathrm{C} \mathrm{cmN}$ reveals common feature of bacterial microcompartment assembly. J Biol Chem. 2012;287:17729-36. https://doi. org/10.1074/jbc.M112.355305.

48. Erbilgin O, Sutter M, Kerfeld CA. The structural basis of coenzyme a recycling in a bacterial organelle. PLoS Biol. 2016;14:e1002399. https://doi. org/10.1371/journal.pbio.1002399.

49. Fan C, Cheng S, Liu Y, Escobar CM, Crowley CS, Jefferson RE, et al. Short Nterminal sequences package proteins into bacterial microcompartments. Proc Natl Acad Sci U S A. 2010;107:7509-14. https://doi.org/10.1073/pnas.0913199107.

50. Fan C, Bobik TA. The N-terminal region of the medium subunit (pdud) packages adenosylcobalamin-dependent diol dehydratase (pducde) into the pdu microcompartment. J Bacteriol. 2011;193:5623-8.

51. Lawrence AD, Frank S, Newnham S, Lee MJ, Brown IR, Xue WF, et al. Solution structure of a bacterial microcompartment targeting peptide and its application in the construction of an ethanol bioreactor. ACS Synth Biol. 2014;3:454-65.

52. Aussignargues $C$, Paasch BC, Gonzalez-Esquer R, Erbilgin O, Kerfeld CA Bacterial microcompartment assembly: the key role of encapsulation peptides. Commun Integr Biol. 2015:8:1-10.

53. Wang $H$, Yan $X$, Aigner $H$, Bracher A, Nguyen ND, Hee WY, et al. Rubisco condensate formation by $\mathrm{CcmM}$ in $\beta$-carboxysome biogenesis. Nature. 2019;566:131-5. https://doi.org/10.1038/s41586-019-0880-5.

54. Cai F, Dou Z, Bernstein SL, Leverenz R, Williams EB, Heinhorst S, et al. Advances in understanding carboxysome assembly in Prochlorococcus and Synechococcus implicate CsoS2 as a critical component. Life. 2015:5:114171. https://doi.org/10.3390/life5021141.

55. Chaijarasphong T, Nichols RJ, Kortright KE, Nixon CF, Teng PK, Oltrogge LM, et al. Programmed ribosomal frameshifting mediates expression of the a-carboxysome. J Mol Biol. 2016;428:153-64. https://doi.org/10.1016/j.jmb.2015.11.017.

56. Liu Y, He X, Lim W, Mueller J, Lawrie J, Kramer L, et al. Deciphering molecular details in the assembly of alpha-type carboxysome. Sci Rep. 2018; 8:15062. https://doi.org/10.1038/s41598-018-33074-x.

57. Dai W, Chen M, Myers C, Ludtke SJ, Pettitt BM, King JA, et al. Visualizing individual RuBisCO and its assembly into carboxysomes in marine cyanobacteria by cryo-electron tomography. J Mol Biol. 2018;430:4156-67. https://doi.org/10.1016/j.jmb.2018.08.013.

58. Parsons JB, Dinesh SD, Deery E, Leech HK, Brindley A, Heldt D, et al. Biochemical and structural insights into bacterial organelle form and biogenesis. J Biol Chem. 2008;283:14366-75. https://doi.org/10.1074/jbc. M709214200.

59. Graf L, Wu K, Wilson JW. Transfer and analysis of Salmonella pdu genes in a range of gram-negative bacteria demonstrate exogenous microcompartment expression across a variety of species. Microb Biotechnol. 2017;11:199-210. https://doi.org/10.1111/1751-7915.12863.

60. Bonacci W, Teng PK, Afonso B, Niederholtmeyer H, Grob P, Silver PA, et al. Modularity of a carbon-fixing protein organelle. Proc Natl Acad Sci U S A. 2012;109:478-83. https://doi.org/10.1073/pnas.1108557109.

61. Baumgart M, Huber I, Abdollahzadeh I, Gensch T, Frunzke J. Heterologous expression of the Halothiobacillus neapolitanus carboxysomal gene cluster in Corynebacterium glutamicum. J Biotechnol. 2017. doi:https://doi.org/10.1 016/j.jbiotec.2017.03.019.

62. Gonzalez-Esquer CR, Newnham SE, Kerfeld CA. Bacterial microcompartment as metabolic modules for plant synthetic biology. Plant J. 2016;87:66-75.

63. Lin MT, Occhialini A, Andralojc PJ, Devonshire J, Hines KM, Parry MAJ, et al. beta-Carboxysomal proteins assemble into highly organized structures in Nicotiana chloroplasts. Plant J. 2014;79:1-12 
64. Long BM, Hee WY, Sharwood RE, Rae BD, Kaines S, Lim Y, et al. Carboxysome encapsulation of the CO 2 - fi xing enzyme Rubisco in tobacco chloroplasts. Nat Commun. https://doi.org/10.1038/s41467-018-06044-0.

65. Parsons JB, Frank S, Bhella D, Liang M, Prentice MB, Mulvihill DP, et al. Synthesis of empty bacterial microcompartments, directed organelle protein incorporation, and evidence of filament-associated organelle movement. Mol Cell. 2010;38:305-15. https://doi.org/10.1016/j.molcel.2010.04.008.

66. Cai F, Bernstein SL, Wilson SC, Kerfeld CA. Production and characterization of synthetic carboxysome shells with incorporated luminal proteins. Plant Physiol. 2016;170:1868-77. https://doi.org/10.1104/pp.15.01822.

67. Lassila JK, Bernstein SL, Kinney JN, Axen SD, Kerfeld C A. Assembly of robust bacterial microcompartment shells using building blocks from an organelle of unknown function. J Mol Biol 2014;426:2217-2228. doi:https://doi.org/1 0.1016/j.jmb.2014.02.025.

68. Liang M, Frank S, Lünsdorf H, Warren MJ, Prentice MB. Bacterial microcompartmentdirected polyphosphate kinase promotes stable polyphosphate accumulation in E. coli. Biotechnol J. 2017:12:1600415. https://doi.org/10.1002/biot.201600415.

69. Jakobson CM, Slininger Lee MF, Tullman-Ercek D. De novo design of signal sequences to localize cargo to the 1,2-propanediol utilization microcompartment. Protein Sci. 2017;26:1086-92.

70. Zakeri B, Fierer JO, Celik E, Chittock EC, Schwarz-linek U, Moy VT. Peptide tag forming a rapid covalent bond to a protein, through engineering a bacterial adhesin. Proc Natl Acad Sci U S A. 2012;109:E690-7.

71. Hagen A, Sutter M, Sloan N, Kerfeld CA. Programmed loading and rapid purification of engineered bacterial microcompartment shells. Nat Commun. 2018;9:1-10. https://doi.org/10.1038/s41467-018-05162-z.

72. Lee MJ, Mantell J, Brown IR, Fletcher JM, Verkade P, Pickersgill RW, et al. De novo targeting to the cytoplasmic and luminal side of bacterial microcompartments. Nat Commun. 2018;9:1-11. https://doi.org/10.1038/s41467-018-05922-x.

73. Ferlez B, Sutter M, Kerfeld CA. A designed bacterial microcompartment shel with tunable composition and precision cargo loading. Metab Eng. 2019;54: 286-91. https://doi.org/10.1016/J.YMBEN.2019.04.011.

74. Hagen A, Plegaria JS, Sloan N, Ferlez B, Aussignargues C, Kerfeld CA. In vitro assembly of diverse bacterial microcompartment shell architectures 2018. doi:https://doi.org/10.1021/acs.nanolett.8b02991.

75. Lee MFS, Jakobson CM, Tullman-ercek D. Evidence for improved encapsulated pathway behavior in a bacterial microcompartment through shell protein engineering. ACS Synth Biol. 2017:6(10):1880-91.

76. Mampel J, Buescher JM, Meurer G, Eck J. Coping with complexity in metabolic engineering. Trends Biotechnol. 2013:31:52-60.

77. Nielsen J, Keasling JD. Engineering cellular metabolism. Cell. 2016;164:118597. https://doi.org/10.1016/j.cell.2016.02.004.

78. Kirby J, Keasling JD. Biosynthesis of plant isoprenoids: perspectives for microbial engineering. Annu Rev Plant Biol. 2009;60:335-55. https://doi. org/10.1146/annurev.arplant.043008.091955.

79. George KW, Alonso-Gutierrez J, Keasling JD, Lee TS. Isoprenoid drugs, biofuels, and chemicals---artemisinin, farnesene, and beyond. In: Schrader J, Bohlmann J, editors. Biotechnology of isoprenoids. Cham: Springer International Publishing; 2015. p. 355-89. https://doi.org/10.1007/10_2014_288.

80. Conrado RJ, Mansell TJ, Varner JD, DeLisa MP. Stochastic reaction - diffusion simulation of enzyme compartmentalization reveals improved catalytic efficiency for a synthetic metabolic pathway. Metab Eng. 2007;9:355-63. https://doi.org/10.1016/j.ymben.2007.05.002.

81. Castellana M, Wilson MZ, Xu Y, Joshi P, Cristea IM, Rabinowitz JD, et al. Enzyme clustering accelerates processing of intermediates through metabolic channeling. Nat Biotechnol. 2014;32:1011-8. https://doi.org/10.1038/nbt.3018.

82. Siu K, Chen RP, Sun Q, Chen L, Tsai S, Chen W. ScienceDirect synthetic scaffolds for pathway enhancement. Curr Opin Biotechnol. 2015;36:98-106. https://doi.org/10.1016/j.copbio.2015.08.009.

83. George KW, Thompson MG, Kim J, Baidoo EEK, Wang G, Benites VT, et al. Integrated analysis of isopentenyl pyrophosphate (IPP) toxicity in isoprenoid-producing Escherichia coli. Metab Eng. 2018;47:60-72. https:// doi.org/10.1016/j.ymben.2018.03.004.

84. Kizer L, Pitera DJ, Pfleger BF, Keasling JD. Application of functional genomics to pathway optimization for increased isoprenoid production. Appl Environ Microbiol. 2008:74:3229-41.

85. Hunt JP, Frey DD, Rao G, Wood DW, Swartz JR, Jewett MC, et al. Cell-free biomanufacturing. Curr Opin Chem Eng. 2018;22:177-83. https://doi.org/10.1 016/j.coche.2018.10.003.
86. Hanson AD, Henry CS, Fiehn O, de Crécy-Lagard V. Metabolite damage and metabolite damage control in plants. Annu Rev Plant Biol. 2016;67:131-52. https://doi.org/10.1146/annurev-arplant-043015-111648.

87. Mouser PJ, Borton M, Darrah TH, Hartsock A, Wrighton KC. Hydraulic fracturing offers view of microbial life in the deep terrestrial subsurface. FEMS Microbiol Ecol. 2016;92:1-18.

88. Borton MA, Hoyt DW, Roux S, Daly RA, Welch SA, Nicora CD, et al. Coupled laboratory and field investigations resolve microbial interactions that underpin persistence in hydraulically fractured shales. Proc Natl Acad Sci U S A. 2018;115:E6585-94. https://doi.org/10.1073/pnas.1800155115.

89. Booker AE, Borton MA, Daly RA, Welch SA, Nicora CD, Hoyt DW, et al. Sulfide generation by dominant Halanaerobium microorganisms in hydraulically fractured shales. mSphere. 2017;2:1-13. https://doi.org/10.1128/ mSphereDirect.00257-17.

90. Liang R, Davidova IA, Marks CR, Stamps BW, Harriman BH, Stevenson BS, et al. Metabolic capability of a predominant Halanaerobium sp in hydraulically fractured gas wells and its implication in pipeline corrosion. Front Microbiol. 2016;7:988. https://doi.org/10.3389/fmicb.2016.00988.

91. Lipus D, Vikram A, Ross D, Bain D, Hammack R, Gulliver D, et al. Predominance and metabolic potential of Halanaerobium spp. in produced water from hydraulically fractured Marcellus shale wells. Appl Environ Microbiol. 2017:83:e02659-16.

92. Bertin Y, Girardeau JP, Chaucheyras-Durand F, Lyan B, Pujos-Guillot E, Harel J, et al. Enterohaemorrhagic Escherichia coli gains a competitive advantage by using ethanolamine as a nitrogen source in the bovine intestinal content. Environ Microbiol. 2011;13:365-77.

93. Srikumar S, Fuchs TM. Ethanolamine utilization contributes to proliferation of Salmonella enterica serovar typhimurium in food and in nematodes. Appl Environ Microbiol. 2011;77:281-90. https://doi.org/10.1128/AEM.01403-10.

94. Steele JFC, Peyret H, Saunders K, Castells-Graells R, Marsian J, Meshcheriakova $Y$, et al. Synthetic plant virology for nanobiotechnology and nanomedicine. Wiley Interdiscip Rev Nanomed Nanobiotechnol. 2017;9:1-18.

95. Caster JM, Patel AN, Zhang T, Wang A. Investigational nanomedicines in 2016: a review of nanotherapeutics currently undergoing clinical trials. Wiley Interdiscip Rev Nanomed Nanobiotechnol. 2017;9:e1416. https:/doi.org/10.1002/wnan.1416.

96. Shen Y, Hao T, Ou S, Hu C, Chen L. Applications and perspectives of nanomaterials in novel vaccine development. Medchemcomm. 2018;9:226-38.

97. Shi J, Kantoff PW, Wooster R, Farokhzad OC. Cancer nanomedicine: progress, challenges and opportunities. Nat Rev Cancer. 2017;17:20-37. https://doi. org/10.1038/nrc.2016.108.

98. Aftab S, Shah A, Nadhman A, Kurbanoglu S, Aysıl Ozkan S, Dionysiou DD, et al. Nanomedicine: an effective tool in cancer therapy. Int J Pharm. 2018;540:132-49.

99. Sun H, Dong Y, Feijen J. Peptide-decorated polymeric nanomedicines for precision cancer therapy. J Control Release. 2018;290:11-27. https://doi. org/10.1016/j.jconrel.2018.09.029.

100. Veronese FM, Pasut G. PEGylation, successful approach to drug delivery. Drug Discov Today. 2005;10:1451-8. https://doi.org/10.1016/S1359-6446(05 03575-0.

101. Bachmann MF, Jennings GT. Vaccine delivery: a matter of size, geometry, kinetics and molecular patterns. Nat Rev Immunol. 2010;10:787-96. https:// doi.org/10.1038/nri2868

102. Zhao L, Seth A, Wibowo N, Zhao CX, Mitter N, Yu C, et al. Nanoparticle vaccines. Vaccine. 2014;32:327-37. https://doi.org/10.1016/j.vaccine.2013.11.069.

103. López-Sagaseta J, Malito E, Rappuoli R, Bottomley MJ. Self-assembling protein nanoparticles in the design of vaccines. Comput Struct Biotechnol J. 2016;14:58-68. https://doi.org/10.1016/j.csbj.2015.11.001.

104. Sutter M, Greber B, Aussignargues C, Kerfeld CA. Assembly principles and structure of a 6.5-MDa bacterial microcompartment shell. Science. 2017;356: 1293-7. https://doi.org/10.1126/science.aan3289.

105. Cai F, Sutter M, Bernstein SL, Kinney JN, Kerfeld C A Engineering bacterial microcompartment shells: chimeric shell proteins and chimeric carboxysome shells ACS Synth Biol 2014. doi:https://doi.org/10.1021/sb500226j.

\section{Publisher's Note}

Springer Nature remains neutral with regard to jurisdictional claims in published maps and institutional affiliations. 